\title{
A Path Forward: Mental Health and the U.S. Pandemic Response
}

\author{
Chirlane I. McCray, ScD (Hon) \\ Linda Rosenberg, MSW
}

\begin{abstract}
The COVID-19 pandemic presents a crisis of mental health in the United States (U.S.) alongside a crisis of infectious disease. Racial inequities in COVID-19 morbidity and mortality have brought health equity to the forefront of public health policy, exacerbating prior inequities in mental health care access and outcomes. This Commentary asserts that policymakers and advocates must prioritize mental health when responding to the pandemic. While the pandemic is an emergency of unprecedented scale, the authors argue that it also is an opportunity to implement broad-based mental health policy reforms in the U.S. that build on the successes of the Affordable Care Act and the Mental Health Parity and Addiction Equity Act. Guided by innovative state and local policies to promote population-level mental health, we outline a series of empirically grounded strategies for federal and state policymakers to promote mental health equity in the wake of COVID-19.
\end{abstract}

\section{Introduction}

The novel coronavirus SARS-CoV-2 (COVID-19) has changed the world in a matter of months. No community in the United States (U.S.) remains untouched by the pandemic. The cause of more than 205,000 deaths and 7.16 million confirmed cases across the nation, ${ }^{1}$ COVID-19 is a public health crisis on a scale that has not been seen in the last 100 years.

More than any calamity, the pandemic and the U.S. response have brought health inequities to the forefront of our national health policy conversation. Black, Indigenous, and other People of Color (BIPOC) have experienced disproportionate rates of COVID-19 mortality and hospitalizations. ${ }^{2}$ Racial inequities in environmental and social factors like air pollution, household overcrowding, and limited access to effective health care are associated with elevated rates of COVID-19 among BIPOC individuals. ${ }^{3}$ Likewise, the BIPOC communities most affected by COVID-19 are among the nation's poorest. ${ }^{2}$

Chirlane I. McCray is the First Lady of New York City, Chair of the Mayor's Fund to Advance New York City, and founder of ThriveNYC. Linda Rosenberg is Director of External Relations at the Columbia University Medical Center Department of Psychiatry and the former President and CEO of the National Council for Behavioral Health.

Address correspondence to Chirlane I. McCray, ScD (Hon), Mayor's Fund to Advance New York City, 181 East End Avenue, New York, NY 10028, USA. Email: FLONYC@cityhall.nyc.gov.

Linda Rosenberg, MSW, External Affairs, Department of Psychiatry, Columbia University Medical Center, New York, USA.

Journal of Behavioral Health Services \& Research, 2020. 161-170. (C) 2020 This is a U.S. government work and not under copyright protection in the U.S.; foreign copyright protection may apply. DOI 10.1007/s11414-020-09747-9 
In addition to the physical health harms posed by COVID-19, the social distancing that is our best defense against community spread increases the potential for population and individual mental health distress. Isolation is associated with a host of physical and mental health conditions and may be compounded by the economic strain the shutdowns precipitated and the collective and individual grief that come with such a profound loss of life. ${ }^{4}$ For individuals living with mental illness, these harms may be more acute. ${ }^{5}$ Taken together, the pandemic and its ripple effects affect the safety of our communities; when one person suffers, we all suffer.

To alleviate and prevent this suffering, our nation has a responsibility to treat the pandemic as a crisis of mental health alongside a crisis of infectious disease and use our current moment as an opportunity to rethink mental health policy at all levels of government. The scope of the pandemic demands that our responses achieve three priority goals. First, we must ensure that effective mental health care is accessible for all, regardless of ability to pay, area of residence, or citizenship status. Second, we must support the mental health of young people as an upstream investment in longterm prevention, since children and youth will experience the residual mental health effects of the pandemic across their lifetimes. And third, we must eliminate inequities in mental health care access and outcomes, and use public policy as a vehicle for equity and racial justice.

In this paper, the authors identify the systemic crisis that the COVID-19 pandemic poses and offer policy strategies to create a more equitable path forward. The authors briefly review the existing mental health inequities the pandemic has exacerbated and describe several evidencebased policies for local-level, population mental health promotion as templates for a national response. Finally, we offer a series of concrete strategies, organized by the three priority goals detailed above, for policymakers across levels of government to structurally reform U.S. mental health care in the wake of COVID-19.

\section{Mental health inequities and the collective trauma of COVID-19}

The effects of COVID-19 on population-level mental health are not yet fully understood, but early reports suggest that the collective shock and social isolation used to protect against the virus are detrimental to mental health. ${ }^{6}$ The racial and economic inequities in COVID-19 morbidity and mortality were exacerbated by underlying health and social inequities, and the inequities in mental health access and outcomes that predate the pandemic are certain to influence the distribution of mental health harm in communities across the U.S. ${ }^{7}$

Stark racial inequities in access to mental health care exist in the U.S. Despite reporting higher rates of psychological distress, Black and Latinx individuals receive care and diagnoses at lower rates than white individuals. ${ }^{8}$ When care is available, Black and Latinx individuals are at greater likelihood of hospitalization and institutionalization compared to white individuals, who more frequently receive community-based treatment. ${ }^{9}$

With regard to pediatric mental health, Black children and youth are less likely than white children to receive quality care in a range of settings. Black justice-involved youth are less likely than their white peers to receive access to mental health care. ${ }^{10}$ Among families engaged with the child welfare system, Black children are less likely than white children to receive mental health treatment. ${ }^{11}$ These inequities in access to care are far reaching to include suicide rates among Black teens and young adults which have increased over the last several decades. ${ }^{12}$

Researchers only have begun to quantify the mental health inequities associated with COVID19. Holding these past inequities in mind, however, we can reassess the disproportionate burden of COVID-19 mortality on BIPOC communities as a collective trauma for which treatment is less available when compared to white communities. When treating this trauma as policymakers, it is imperative that mental health services are delivered in ways that work to undo underlying inequities and do not cause additional harm. As policymakers develop a COVID-19 recovery, they 
must look forward at how the pandemic will reshape mental health care and backward at the historical legacy of injustice in mental health.

\section{Public policy to promote population mental health}

The confluence of structural racism and preexisting health inequities with COVID-19 has disproportionately affected marginalized populations. As the nation reckons with the toll of the pandemic (trauma, loss, anxiety, and depression), policymakers have an opportunity to address longstanding racial inequities. Similar to the transformative policies to reduce inequity made possible by the Great Depression, the COVID-19 pandemic presents an opportunity for federal and state policymakers to reimagine mental health care and build on the successes of the Affordable Care Act and the Mental Health Parity and Addiction Equity Act.

In recent years, local governments have actively and innovatively modeled the use of public policy for population mental health promotion. In 2015, New York City (NYC) launched ThriveNYC, a mental health policy platform that positioned mental health equity at the center of urban governance and established a portfolio of initiatives to expand access to preventive and direct mental health care. In parallel to ThriveNYC, a consortium of over 200 municipal and county governments have formed the Cities Thrive Coalition and pledged to elevate mental health as a central policy issue in their jurisdictions. Through the Coalition, cities worldwide have built out municipal mental health policy in the model of ThriveNYC, notably ThriveLDN in London and Mind Shift in Stockholm. ${ }^{13}$ The goals and programs that guide and comprise ThriveNYC and the Cities Thrive Coalition are described in detail elsewhere. ${ }^{14,15}$ We briefly present three examples from NYC to illustrate how public policy can attend to population mental health in ways that are scalable and meet the demands of the pandemic.

To ensure that mental health care is accessible for all, New York City implemented NYC Care in 2019, a no- or low-cost health care program for undocumented, low-income, and uninsured individuals. ${ }^{16}$ Lack of coverage and high costs are established barriers to accessing mental health care and are associated with poor mental health outcomes, particularly among undocumented individuals $;^{17} \mathrm{NYC}$ Care eliminates those barriers. Although federal insurance coverage expansion models remain debated, ${ }^{18}$ several states - including Washington and New Mexico- have begun to expand coverage at the state level, a promising model to address challenges posed by COVID-19. ${ }^{19}$

To promote lifelong mental health for young people, early intervention is crucial. ${ }^{20}$ Guided by this principle, NYC introduced a Social-Emotional Learning (SEL) curriculum into all public schools for students from pre-kindergarten through 12th grade. ${ }^{16}$ The curriculum includes didactic and experiential components to develop social, emotional, and behavioral regulation skills. Supports for parents and caregivers are emphasized to break cycles of intergenerational mental health stigma and trauma. The use of SEL curricula in other jurisdictions is associated with improved mental health outcomes, academic performance, and school attendance, as well as reduced disciplinary incidents. ${ }^{21}$ In the context of COVID-19, from which children and youth are under acute emotional duress, ${ }^{22}$ building mental health promotion into education can equip young people to cope with distress caused by the pandemic.

Finally, to reduce mental health inequities, NYC established the Sisters Thrive, Brothers Thrive, and Latinx Thrive initiatives in 2017 and 2018. ${ }^{16}$ These initiatives bring together historically Black- and Latinx-led community, educational, professional, and advocacy organizations to train Black and Latinx individuals in Mental Health First Aid (MHFA), a curriculum for laypersons to identify and respond to mental health crises in their communities. MHFA training is associated with increased bystander intervention and reduce stigma toward mental health care. ${ }^{23}$ By focusing MHFA expansion to Black and Latinx communities, NYC aims to promote supportive communitybased care for historically underserved populations. ${ }^{24}$ 
Local governments across the U.S. have followed NYC's lead and centered mental health in local governance. King County, Washington, for which Seattle is the county seat, announced a sweeping mental health crisis care plan in 2016 that enhanced the county's services for acute mental illness. ${ }^{25}$ King County expanded this work in response to COVID-19 to integrate mental health with primary care. Likewise, Boston, MA, has incorporated universal mental health screening and SEL curricula into public schools through its Comprehensive Behavioral Health Model (CBHM). ${ }^{26}$ The CBHM positions Boston to support youth and families through and beyond the pandemic. Collectively, the local initiatives we have highlighted demonstrate how federal and state policymakers could respond to COVID-19 in ways that promote access to care, prioritize long-term outcomes, and build mental health equity.

\section{Strategies to build mental health equity in the wake of COVID-19}

The COVID-19 pandemic has placed public health at the forefront of federal, state, and local policy. We suggest that it remains crucial to prioritize mental health to mitigate negative outcomes stemming from the crisis. Public policy is a key tool to improve population mental health and wellness. As such, we present a range of strategies for mental health recovery after COVID-19 (Table 1).

Priority goal 1: Ensure access to mental health care for all. Policymakers have a responsibility to guarantee mental health coverage for all as they develop and implement a long-term COVID-19 recovery. The Families First Coronavirus Response Act and the Coronavirus Aid, Relief, and Economic Security Act include provisions to extend universal testing and services for COVID-19 without cost-sharing. ${ }^{27}$ It is imperative that future enhancements in coverage extend to mental health, as the mental health effects of the pandemic are likely to be long-term and may not yet be realized.

In the absence of additional federal recovery packages, state and local governments are positioned to expand mental health coverage through ballot initiatives or by funding direct service. ${ }^{28}$ Denver, CO, passed the Caring for Denver ballot initiative in 2018 to levy a $\$ 0.25$ sales tax to generate revenue dedicated toward mental health care. CA increased funding for mental health care through the Mental Health Services Act, which levies a $1 \%$ income tax on income in excess of $\$ 1$ million. In addition to increasing revenue to fund coverage expansion, all levels of government can utilize regulatory authorities to increase access to existing services and function as coordinating bodies to streamline care.

At the federal level, policymakers have several tools readily available. The Centers for Medicare and Medicaid Services (CMMS) could use regulatory authority to eliminate cost-sharing requirements for furnished mental health and substance use disorder services and increase Medicaid reimbursement rates for mental health care. While parity remains essential, increased cost-sharing can make care unaffordable for individuals with co-occurring disorders. ${ }^{29}$

Likewise, low Medicaid reimbursement rates place strain on mental health providers. ${ }^{30}$ Eliminating cost-sharing requirements while increasing reimbursement rates could expand access among lowincome and underinsured populations and increase provider ability to deliver quality care.

Furthermore, the U.S. Department of Labor (DOL) could leverage its enforcement authority to sanction states and payors that do not adhere to federal parity requirements. Parity requirements are not universally honored, which limits the necessary care that consumers can access. ${ }^{31}$ At the federal level, DOL retains the authority to levy financial sanctions as an incentive to increase parity and could use this authority to guarantee access in line with the law. In the context of the pandemic, policymakers must ensure that insurance costs and regulatory barriers do not hamper access to care. 
Table 1

Strategies to Build Mental Health Equity After COVID-19

Priority goal 1: ensure access to mental health care for all Nationwide expansion of Certified Community Behavioral Health Clinics

Enhanced enforcement authority to financially sanction payers and providers not adhering to federal parity requirements Increased Medicaid reimbursement rates for mental health care, with designated allocations for mental health resources in Medicaid enhancements Integrate mental health services across settings: primary care, schools, correctional facilities, and workplaces

Eliminate cost-sharing requirements for mental health and substance use disorder services

Federal government

Federal and state governments

Federal and state governments Priority goal 2: support the mental health of young people Universal mental health school screening from kindergarten through 12th grade

Mental health counseling available in every school Social-emotional learning curriculum in every school implemented to SAMHSA standards

Healing-informed trauma training for teachers

Expansion of Youth and Teen Mental Health First Aid Improve school climate and culture through additional financing for equity-building strategies

Change regulations to authorize use of and reimbursement for mobile apps and other tech tools to engage youth and

State and local governments

Federal government

State governments

State and local governments State and local governments

State and local governments; professional organizations

Federal and state governments Federal and state governments

State governments caregivers in therapy (e.g., text therapy)

Priority goal 3: eliminate inequities in mental health care access and outcomes Support SAMHSA, HRSA, and DOL grants to build out the Federal government mental health workforce in underserved and understaffed settings

Establish a Communities of Color Peer Workforce Initiative Federal government to develop a community-based mental health workforce in high-need areas

Establish a HRSA funding program for fast-tracked cultural Federal government competency training for mental health providers as an immediate response to COVID-19

Support tuition remission to incentivize young people of color to enter the mental health professions

Institute a scoring system for SAMHSA and HRSA grants that prioritizes community-based programs in communities of color

Require federal SAMHSA and HRSA grantees to engage task-sharing as part of program development Incentivize the philanthropic sector to partner with

Federal government

Federal government

Federal government

Federal, state, and local 
government to fund mental health interventions with high governments upstart costs

Prioritize funding mental health crisis response systems that Federal government do not rely on justice system actors

Source: authors' analysis

Federal and state authorities could work together to expand the reach of Certified Community Behavioral Health Clinics (CCBHCs) which consolidate mental health and substance use disorder services for people with serious mental illness and addictive disorders while adhering to stringent federal reporting requirements. ${ }^{32}$ Federal criteria for CCBHCs were established as part of the 2014 Excellence in Mental Health Act. While the use of these facilities has expanded in many states, most communities are left without access to CCBHCs, despite evidence indicating that CCBHCs are associated with increased service utilization and preventive screening, as well as reduced costs. $^{33}$ Congress could increase funding and priority for CCBHCs, with appropriations administered by the Department of Health and Human Services (HHS) to incentivize states to adopt CCBHCs as a core component of Medicaid expansion. As a response to COVID-19, $\mathrm{CCBHCs}$ are useful for rural or low-resourced jurisdictions that require additional support to scale mental health services.

Lastly, state and local governments can partner to increase collaborative mental health treatment and access to screening in primary care. In 2016, CMMS approved reimbursement for collaborative mental health services delivered in primary care, expanding reimbursement criteria for rural settings and Federally Qualified Health Centers (FQHCs). However, provider uptake has been slow. ${ }^{34}$ An expanded mental health workforce, as described below, can facilitate the integration of onsite case managers to support primary care providers (PCPs). The use of telehealth can expand access to psychiatric consultation in primary care. Notably, primary care integration is an effective means to reach older adults, who otherwise may not access mental health care. ${ }^{35}$

Priority goal 2: Support the mental health of young people. Children's collective and individual trauma from COVID-19, including witnessing mass death and engaging in long-term social isolation, present an urgent need for mental health care as the current generation grows up under and after the pandemic. As the primary touchpoint between government and youth, education must adapt to meet this need. Although state and local governments control the operations of U.S. public education, the U.S. Department of Education (DOE) has considerable influence as a funding and standard-setting body to promote and support the integration of mental health care into education nationwide.

One strategy is education-based universal mental health screening and access to mental health services from kindergarten to 12th grade. Social and emotional development is as important as physical development; screening for mental health must be routinized as part of human development. By identifying childhood mental health issues early and referring children to necessary support, the education system can prevent future mental health challenges.

A screening program, without the school's ability to provide access to mental health services, will not improve children's mental health outcomes. Thus, successful screening requires in tandem funding for sufficient access to mental health care, such as counselors in schools, telemental health, 
or other digital mental health care, such as text-based counseling. In particular, building a mental health safety net into education creates a lifeline for young people who lack support in the home or are housing unstable. Prioritizing funding for screening and concomitant services is an opportunity for DOE to model best practices for states and build out private sector partnerships to integrate digital tools into schools.

School curricula and in-school training can promote pediatric mental health. Social-emotional learning and Youth and Teen Mental Health First Aid are associated with improved mental health awareness and reduced stigma among youth. ${ }^{22,}{ }^{36}$ The Substance Abuse and Mental Health Services Administration (SAMHSA) has released standards for the use of SEL in schools, but this guidance remains voluntary. ${ }^{37}$ DOE could require that implementation of SEL in schools meets SAMHSA standards. While several localities have integrated SEL and MHFA into schools systemwide, scaling these interventions nationally would require federal incentives and partnerships with organized labor groups like the American Federation of Teachers and National Education Association, as well as non-governmental bodies like the Common Core State Standards Initiative, National Governors Association, and the National Council for Behavioral Health.

The primary link between schools and children and families, teachers have a key role in improving student mental health. An investment in the nation's teachers is an investment in the nation's children. When children return to school after COVID-19 closures are lifted, teachers must be equipped to identify and address the signs and symptoms of poor mental health and trauma among students. Healing-informed training can equip teachers to address the residual trauma of COVID-19 in the classroom in a therapeutic and non-judgmental manner. SAMHSA has issued guidance for trauma-informed practices in the workplace, which have been adapted successfully to educational settings. ${ }^{38}$ To expand the reach of these programs, DOE could support states to fund healing-informed training in school districts. Partnerships with professional organizations and state certification bodies could be used to increase the reach of healing-informed training for educa tors.

Priority goal 3: Eliminate inequities in mental health care access and outcomes. COVID-19 has exacerbated the racial and economic inequities endemic to U.S. health care systems. ${ }^{8}$ Undoing these inequities can be accomplished through a combination of robust federal regulatory and legislative action. While led by the federal government, many of these strategies would engage state and local governments as part of implementation and services delivery. Intergovernmental collaboration has been instrumental in our nation's health and social policy successes, such as reducing veteran homelessness, ${ }^{39}$ and collaboration is critical as we move to eliminate inequities in mental health.

As part of maintaining a federal focus on mental health equity, SAMHSA, the Health Resources and Services Administration (HRSA), and DOL could establish grant funding mechanisms for rapid and widespread cultural and clinical competency training for health care professionals as a short-term response to COVID-19. Such training, which teach providers to recognize the social determinants of health as an aspect of care and engage patients from cultural backgrounds that are not their own, are effective in improving patient satisfaction and provider engagement. ${ }^{40}$ The delivery of the training could be accomplished in partnership with professional medical, nursing, psychological, and social work bodies.

However, competency training alone is not enough to reduce inequities. ${ }^{41}$ Estimates suggest that only $5 \%$ of physicians are Black, a gross underrepresentation in the health care workforce. ${ }^{42}$ While a range of pipeline programs for Black, Indigenous, and other People of Color exist to support health care workforce development, the federal government has not invested in BIPOC mental health workforce development at the scale necessary to respond to COVID-19. Training BIPOC individuals as mental health professionals is essential to eliminate inequities in care. ${ }^{41}$ Through tuition remission and educational incentive programs that have been implemented successfully in 
other fields (e.g., public service, law, and the military), the federal government could incentivize BIPOC young people to enter the mental health workforce. A time-limited service component (e.g., three or five years) with structured career pathways to nursing schools or four-year colleges would promote advancement within the field. Such a program could build collaborative care staffing in low-resource, high-need settings (e.g., FQHCs or rural health systems) to help alleviate the burden faced by PCPs to deliver mental health care.

In parallel to training BIPOC mental health professionals, the federal government could establish a Communities of Color Peer Workforce to leverage the ability of peers to deliver community-based care. Peer mental health models, which integrate people with lived experience into professionalized treatment teams and leverage the trust between peers and patients to deliver care, are associated with improved mental health and social outcomes and are an effective means to engage individuals who have faced discrimination within or exclusion from health care systems. ${ }^{43}$ Investing in the widespread use of mental health peers would fill gaps in care and establish an employment pathway for individuals with histories of mental illness. This workforce could be deployed to the communities with the least provider coverage and the greatest inequities in access and outcomes.

To ensure the fidelity of investments in BIPOC mental health promotion through SAMHSA and HRSA, the federal government could revise agency grant systems to prioritize BIPOC communities. Additionally, federal grants could stipulate the incorporation of evidence-based, community-oriented strategies to reduce inequities in mental health, such as task-sharing, a strategy to engage laypersons and non-professional care workers in community-based mental health care and is associated with improved access to care and reduced costs. ${ }^{44}$ In addition to federal grants, the philanthropic sector could be engaged to target donations toward mental health, a historically underfunded area. ${ }^{45}$ Philanthropy is well positioned to supplement funding toward technologybased care or other services with high upstart costs, with operations costs later shared with the government through innovative mental health partnerships.

Finally, it is important that new strategies build a network of support outside of the justice system, which remains the largest provider of mental health services in the U.S. ${ }^{46}$ While public safety remains an important component of promoting population mental health, new investments in crisis response must be made to engage community-based support without increasing individual justice involvement. Alternatives to policing through the use of trained mental health professionals for de-escalation and connection to care are important to promote BIPOC health and safety. Several successful models exist and could be brought to scale nationally through adequate federal investments. ${ }^{47}$

\section{Implications for Behavioral Health}

As the epidemiologic and clinical scope of the COVID-19 pandemic evolves, policymakers and advocates must formulate an unwavering response grounded in health equity and racial justice to mitigate associated mental health harms. We must make sure all individuals are safe from harm, never forgetting that BIPOC communities are on the front lines of the pandemic. The scale of the crisis demands that we take action toward national mental health recovery now.

We have offered a series of empirically grounded strategies for federal, state, and local policymakers to work toward such a recovery. These strategies build on best practices across the nation and are organized across three priority goals. First, guaranteeing access to mental health care for all. Second, supporting the mental health of young people as a preventive investment in our future. Third, eliminating the inequities that leave the hardest hit communities to bear the majority of harm. The necessary pieces to implement this agenda are available, only requiring the will and political leadership.

Fundamentally, we believe mental health care is a human right. With this axiom as our starting and ending points, we call on policymakers and advocates to come together to deliver the care we 
need and deserve. There is no time to waste, but if we act now and we act boldly, mental health equity in the U.S. is within reach.

\section{References}

1. Johns Hopkins University. Coronavirus Resource Center. Available online at: https://coronavirus.jhu.edu. Accessed on October 5, 2020.

2. Bibbins-Domingo K. This time must be different: Disparities during the COVID-19 pandemic. Annals of Internal Medicine. 2020;M20-2247.

3. Millett GA, Jones AT, Benkeser D, et al. Assessing differential impacts of COVID-19 on black communities. Annals Epidemiology. 2020;47:37-44.

4. Hämmig O. Health risks associated with social isolation in general and in young, middle and old age. PLoS One. 2019;14(7):e0219663.

5. Hamada K, Fan X. The impact of COVID-19 on individuals living with serious mental illness. Schizophrenia Research. 2020. https:// doi.org/10.1016/j.schres.2020.05.054.

6. Dong L, Bouey J. Public mental health crisis during COVID-19 pandemic China. Emerging Infectious Diseases. 2020;26(7):16161618.

7. Dorn AV, Cooney RE, Sabin ML. COVID-19 exacerbating inequalities in the U.S. Lancet. 2020;395(10232):1243-1244.

8. Breslau J, Kendler KS, Su M, et al. Lifetime risk and persistence of psychiatric disorders across ethnic groups in the United States. Psychological Medicine. 2005;35(3):317-327.

9. Snowden LR, Cheung FK. Use of inpatient mental health services by members of ethnic minority groups. American Psychologist. 1990;45(3):347-55.

10. Wojciechowski TW. Racial disparities in community mental health service use among juvenile offenders. Journal of Racial Ethnic Health Disparities. 2019;6(2):393-400.

11. Wells R, Hillemeier MM, Bai Y, et al. Health service access across racial/ethnic groups of children in the child welfare system. Child Abuse \& Neglect. 2009;33(5):282-292.

12. Robinson WL, Case MH, Whipple CR, et al. Culturally grounded stress reduction and suicide prevention for African American adolescents. Practice Innovations. 2016;1(2):117-128.

13. Kousoulis AA, Goldie I. Mapping mental health priorities in London with real-world data. Lancet Psychiatry. 2017;4(10):e24.

14. Belkin G, McCray C. ThriveNYC: Delivering on mental health. American Journal of Public Health. 2019;109(S3):S156-S163.

15. McCray C. Consumer and family perspectives in advancing mental health equity. Psychiatric Clinics of North America. 2020;43(3):539-554.

16. Jaffe S. NYC guarantees health care to all. Lancet. 2019;393(10169):e3-e4.

17. Walker ER, Cummings JR, Hockenberry JM, et al. Insurance status, use of mental health services, and unmet need for mental health care in the United States. Psychiatric Services. 2015;66(6):578-584.

18. Glied SA, Lambrew JM. How democratic candidates for the presidency in 2020 could choose among public health insurance plans. Health Affairs 2018;37(12):2084-2091.

19. Sparer M. Redefining the "public option": Lessons from Washington State and New Mexico. The Milbank Quarterly. 2020;98(2):260-278.

20. Membride H. Mental health: Early intervention and prevention in children and young people. British Journal of Nursing. 2016;25(10):552-4-556-7.

21. Lawson GM, McKenzie ME, Becker KD, et al. The core components of evidence-based social emotional learning programs. Prevention Science. 2019;20(4):457-467.

22. Fegert JM, Vitiello B, Plener PL, et al . Challenges and burden of the Coronavirus 2019 (COVID-19) pandemic for child and adolescent mental health: A narrative review to highlight clinical and research needs in the acute phase and the long return to normality. Child Adolescent Psychiatry Mental Health. 2020;14:20.

23. Morgan AJ, Ross A, Reavley NJ. Systematic review and meta-analysis of Mental Health First Aid training: Effects on knowledge, stigma, and helping behaviour. PLoS One. 2018;13(5):e0197102.

24. Office of the Surgeon General (U.S.), Center for Mental Health Services (U.S.), National Institute of Mental Health (U.S.). Mental Health: Culture, Race, and Ethnicity: A Supplement to Mental Health: A Report of the Surgeon General. Rockville: Substance Abuse and Mental Health Services Administration (U.S.), 2001.

25. King County Community Alternatives to Boarding Task Force. Community Alternatives to Boarding Task Force final report. Seattle: Office of the King County Executive, 2016.

26. Boston Public Schools. Comprehensive Behavioral Health Model Prospectus. Boston: City of Boston, 2015.

27. Keith K. New Guidance to Implement COVID-19 Coverage Requirements and More. Health Affairs Blog. Available online at: https:// www.healthaffairs.org/do/10.1377/hblog20200413.78972/full/. Accessed on July 5, 2020.

28. Glied S. Options for dialing down from single payer. American Journal Public Health. 2019;109(11):1517-1520.

29. Jost T. Implementing Health Reform: The Individual Market; Mental Health and Substance Use Parity. Health Affairs Blog. Available online at: https://www.healthaffairs.org/do/10.1377/hblog20131109.035299/full/. Accessed on July 3, 2020.

30. Cummings JR. Rates of psychiatrists' participation in health insurance networks. JAMA. 2015;313(2):190-191.

31. McGuire TG. Achieving mental health care parity might require changes in payments and competition. Health Affairs (Millwood). 2016;35(6):1029-1035. 
32. Rosenberg L. Community services for mental illnesses and substance use disorders: The moral test of our time. Journal of Behavioral Health Services and Research. 2018;45(2):157-159.

33. U.S. Department of Health and Human Services. Certified Community Behavioral Health Clinics Demonstration Program Report to Congress, 2018. Washington: Office of the Assistant Secretary for Planning and Evaluation, 2019.

34. Carlo AD, Unützer J, Ratzliff ADH, et al. Financing for collaborative care - A narrative review. Current Treat Options Psychiatry. 2018;5(3):334-344.

35. Bartels SJ, DiMilia PR, Fortuna KL, et al. Integrated care for older adults with serious mental Illness and medical comorbidity: Evidence-based models and future research directions. Psychiatry Clinics of North America. 2018;41(1):153-164.

36. Hart LM, Mason RJ, Kelly CM, et al. 'Teen Mental Health First Aid': A description of the program and an initial evaluation. International Journal Mental Health System. 2016;10:3.

37. Substance Abuse and Mental Health Services Administration. Ready, Set, Go, Review: Screening for Behavioral Health Risk in Schools. Rockville: Office of the Chief Medical Officer, Substance Abuse and Mental Health Services Administration, 2019.

38. Center for Substance Abuse Treatment (U.S.). Trauma-Informed Care in Behavioral Health Services: Treatment Improvement Protocol (TIP) Series, No. 57. Rockville: Substance Abuse and Mental Health Services Administration (U.S.), 2014.

39. McGraw SA, Larson MJ, Foster SE, et al. Adopting best practices: lessons learned in the Collaborative Initiative to Help End Chronic Homelessness (CICH). Journal of Behavioral Health Services and Research. 2010;37(2):197-212.

40. Jongen C, McCalman J, Bainbridge R. Health workforce cultural competency interventions: A systematic scoping review. BMC Health Services Research. 2018;18(1):232.

41. Shen MJ, Peterson EB, Costas-Muñiz R, et al. The effects of race and racial concordance on patient-physician communication: A systematic review of the literature. Journal of Racial and Ethnic Health Disparities. 2018;5(1):117-140.

42. Noonan AS, Velasco-Mondragon HE, Wagner FA. Improving the health of African Americans in the U.S.: An overdue opportunity for social justice. Public Health Review 2016;37:12.

43. Sledge WH, Lawless M, Sells D, et al. Effectiveness of peer support in reducing readmissions of persons with multiple psychiatric hospitalizations. Psychiatric Services. 2011;62(5):541-4.

44. Raviola G, Naslund JA, Smith SL, et al. Innovative models in mental health delivery systems: Task sharing care with non-specialist providers to close the mental health treatment gap. Current Psychiatry Reports. 2019;21(6):44.

45. Ward K, Evans-Chase M, La H, et al. Health in Mind: A Philanthropic Guide for Mental Health and Addiction. Philadelphia: Center for High Impact Philanthropy, University of Pennsylvania, 2020.

46. Al-Rousan T, Rubenstein L, Sieleni B, et al. Inside the nation's largest mental health institution: A prevalence study in a state prison system. BMC Public Health. 2017;17(1):342.

47. Council of State Governments Justice Center. Behavioral Health Diversion Interventions: Moving from Individual Programs to a Systems-Wide Strategy. New York: Council of State Governments Justice Center, 2019.

Publisher's Note Springer Nature remains neutral with regard to jurisdictional claims in published maps and institutional affiliations. 